\title{
CONSIDERAÇÕES SOBRE O MODELO DE ANÁLISE DO DISCURSO DE PATRICK CHARAUDEAU
}

Cláudio Marques Martins Nogueira ${ }^{\mathrm{i}}$

$\underline{\mathrm{cmmn} @ \text { uol.com.br }}$

\section{RESUMO}

$\mathrm{O}$ artigo discute o modelo de análise do discurso de Patrick Charaudeau. São destacados quatro compromissos ou preocupações teóricas que parecem orientar - embora, nem sempre de maneira explícita - o trabalho desse autor. Destacase, em primeiro lugar, seu compromisso com a articulação entre os planos situacional e lingüístico. Aponta-se, em segundo lugar, o modo como esse autor integra em seu modelo os planos macro e microssocial. Em terceiro lugar, sublinha-se a grande importância atribuída pela perspectiva de Charaudeau às interações sociais. Finalmente, considerase o modo particular como o autor concebe a intencionalidade dos sujeitos envolvidos nos atos de linguagem.

\begin{abstract}
The article discusses the discourse analysis model of Patrick Charaudeau. We emphasize four commitments or theoretical concerns that seem to orient the work of this author - although not always in an explicit manner. We discuss, first, his commitment with the articulation between the situational plane and the linguistic plane. Second, we note how the author integrates in his model the macro and micro-social planes. Third, we highlight the great importance attributed to social interaction in Charaudeau's perspective. Finally, we consider how the author conceives intentionality of subjects involved in language acts.
\end{abstract}

\section{Introdução}

As Ciências Humanas tem se orientado, nas duas últimas décadas, por um desafio teórico básico: construir um sistema capaz de articular conceitualmente os planos do ator e da estrutura social. O problema da articulação entre esses dois planos, de uma forma ou de outra, sempre foi posto pela teoria social. A grande diferença talvez seja, no entanto, que, atualmente, as respostas unilaterais, que privilegiam deliberadamente um desses dois planos em detrimento do outro, passaram a ser menos aceitas na comunidade científica mundial. Cada vez mais, busca-se compreender a ponte, a mediação entre o plano do sujeito, com suas intenções, preferências e estratégias mais ou menos conscientes e o plano das estruturas sociais, das coletividades, dos constrangimentos externos.

A proposta de análise do discurso desenvolvida por Patrick Charaudeau insere-se, sem dúvida alguma, nesse esforço amplo das Ciências Humanas de construção de um modelo multidimensional de compreensão da realidade social. Seu objetivo, no entanto, cabe observar, não é a construção de uma teoria geral e abstrata sobre os mecanismos de articulação entre estruturas e atores sociais. Diferentemente disso, Charaudeau esforça-se para constituir uma estratégia operacional de análise dos discursos capaz de contemplar, de modo integrado, as múltiplas dimensões envolvidas num ato de linguagem. Embora ele chegue a estabelecer proposições gerais sobre o modo de articulação entre vários planos da realidade social, toda sua teorização é desenvolvida a serviço de um modelo alternativo de análise empírica do discurso que ele pretende inaugurar.

Neste artigo, identificam-se alguns compromissos teóricos básicos, nem sempre explicitados, que marcam a abordagem de Charaudeau e aponta-se o modo como esses se traduzem num conjunto determinado de conceitos e em estratégias específicas de análise empírica do discurso.

$\mathrm{O}$ maior desses compromissos é, certamente, com a articulação entre os planos situacional, concernente à realidade social em que o discurso é produzido, e lingüístico, referente às características internas do discurso. Charaudeau procura evitar tanto as abordagens que enfatizam excessivamente o plano do contexto social, em prejuízo da análise propriamente lingüística, quanto as que tendem a focalizar unilateralmente a dimensão lingüística, sem considerar suficientemente as condições sociais de produção do discurso.

Outro compromisso teórico importante que pode ser identificado na abordagem de Charaudeau refere-se ao modo de articulação dos planos macro e microssocial. Charaudeau preocupa-se em não conceber essa articulação de uma forma mecânica e determinista. Ele procura não deduzir, diretamente, as intenções, ações e, portanto, o próprio discurso produzido pelos sujeitos num momento concreto de interação social, da posição desses sujeitos na estrutura social mais ampla. A passagem de um plano ao outro não é concebida como automática, ou seja, as características do discurso produzido e o curso do ato de linguagem como um todo não são explicados, diretamente, em função das posições sociais dos parceiros envolvidos ou das características do contexto social mais amplo.

Essa recusa ao determinismo ou mecanicismo conduz Charaudeau, ainda, a uma terceira preocupação ou compromisso teórico fundamental: o compromisso com a dimensão da interação social. De acordo com sua perspectiva, é no encontro com o outro que as identidades e recursos sociais dos parceiros são ou não utilizados e que o discurso se constrói de uma forma ou de outra. A forma de interação dos parceiros e o discurso que eles produzem não estão predefinidos em relação 
ao momento de interação. Os sujeitos, partem, é claro, de uma série de expectativas relativas à forma de organização de cada tipo de encontro linguageiro e ao tipo de discurso esperado em cada caso. Essas expectativas só se realizam, no entanto, a partir de um processo dinâmico de interação social no qual a natureza do próprio intercâmbio e do discurso a ser produzido vão sendo continuamente redefinidos.

Finalmente, cabe ressaltar o compromisso de Charaudeau com uma concepção da intencionalidade dos sujeitos bastante sofisticada. Os sujeitos, na concepção do autor, não são nem meros portadores de uma intencionalidade sistêmica que os domina, sem que tenham consciência disso - como é o caso em alguns dos outros modelos de análise do discurso - nem seres plenamente conscientes, que agem racionalmente, livres de qualquer adesão identitária ou normativa previamente estabelecida. Por um lado, os sujeitos em Charaudeau são caracterizados como tendo um "projeto de fala", ou seja, objetivos mais ou menos claros que os motivam na construção de seus discursos e que são perseguidos estrategicamente. Por outro lado, no entanto, Charaudeau não deixa, em momento algum, de caracterizar esses sujeitos como seres socialmente situados, portadores de identidades e de recursos específicos que os condicionam na definição de seus cursos de ação.

\section{A crítica de Charaudeau aos outros modelos de análise do discurso}

A proposta de análise do discurso de Charaudeau define-se em função de um desafio básico: articular as dimensões psicossociológicas envolvidas num ato de linguagem - especialmente, a identidade e os papeis sociais dos interlocutores, as relações sociais em que estão inseridos, os objetivos, as representações e as expectativas dos parceiros - com as dimensões propriamente lingüísticas ou linguageiras que o caracterizam, ou seja, com as propriedades formais e semânticas do discurso em questão.

$\mathrm{O}$ alcance e a especificidade dessa proposta de Charaudeau tornam-se mais claros, em primeiro lugar, observando-se o modo como ele se afasta e, assim, se distingue das demais alternativas de análise do discurso. Essas alternativas não são caracterizadas por ele como ilegítimas ou desprezíveis, mas apenas definidas como parciais, limitadas, incapazes de abordar os fatos da linguagem nas suas múltiplas dimensões. Nos termos de Charaudeau (1996, p.20), cada uma dessas perspectivas "descreve os fatos da linguagem como se fossem portadores de um só jogo de significação da parte de um só sujeito falante" sendo que, ao contrário, esses fatos "são portadores de vários jogos e eles testemunham um sujeito complexo, na verdade, dividido".

Assim, pode-se dizer que as críticas de Charaudeau não se dirigem tanto à contribuição substantiva e específica trazida por cada uma das alternativas de análise do discurso, mas, sobretudo, ao caráter unilateral dessas abordagens. Isso fica especialmente claro em Charaudeau (1999a). Nesse texto, o autor define - em função do objeto que cada uma constrói, do modo como concebem os sujeitos e do tipo de corpus que organizam - três grandes problemáticas presentes na análise do discurso: cognitiva e categorizante; comunicativa e descritiva; e representacional e interpretativa ${ }^{\text {ii }}$. Charaudeau analisa cada uma dessas problemáticas (que, talvez, também, pudessem ser chamadas de abordagens ou campos de pesquisa), identifica seus problemas e seus limites, mas, em momento algum, chega a rejeitar qualquer uma delas. Pelo contrário, na parte final do artigo, quando ele se situa diante dessas três problemáticas, ele reconhece a importância de cada uma delas e admite que se serve, no seu próprio trabalho, das três.

Da mesma forma, no texto de 1996, Charaudeau analisa criticamente uma série de abordagens da análise do discurso buscando explicitar, fundamentalmente, a incapacidade dessas abordagens de tratar, simultaneamente, de forma articulada, os espaços externo e interno (situacional e lingüístico) nos quais se realiza o ato de linguagem. Ele critica, por um lado, às abordagens que priorizam a dimensão lingüística do discurso e que se interessam, predominantemente, pelo que ele, no texto de 1999a, denomina, uma problemática cognitiva e categorizante. A ênfase, no caso dessas abordagens, é concedida aos mecanismos internos do discurso, ao modo como esse é organizado, à análise das palavras e dos recursos lingüísticos utilizados no discurso. As características psicossociais dos sujeitos produtores do discurso e a natureza do contexto social no qual esse é produzido tendem a ser negligenciadosiii. O sujeito social concreto é, de certa forma, reduzido à sua dimensão cognitiva, ou seja, à "sua aptidão em produzir e reconhecer operações e articulações discursivas" (1999a, p. 33). A identidade psicossocial dos sujeitos não é diretamente considerada ou, pelo menos, não o é de forma satisfatória. Com relação ao contexto, abstrai-se das situações reais de fala, e considera-se prioritariamente o contexto lingüístico, ou seja, os parâmetros e constrangimentos relacionados com a própria estrutura do texto (discurso) em questão.

Charaudeau dirige, por outro lado, várias críticas às abordagens que priorizam a dimensão situacional na análise do discurso. Em primeiro lugar, critica as correntes chamadas por ele de sociológicas ou correlacionistas, que têm como referência a obra de Bourdieu e que buscam explicar a atuação dos sujeitos nos atos de linguagem e os discursos produzidos por eles em função da localização dos mesmos nas estruturas de poder e privilégio econômico e cultural. No caso dessas correntes, o que Charaudeau rejeita é, sobretudo, o determinismo sociológico, a tendência a subordinar, de forma mais ou menos direta, a esfera do discurso às estruturas sociais. Em segundo lugar, Charaudeau (1999a), critica as correntes mais tradicionais de análise do discurso que, em alguma medida, subordinam a intencionalidade e a produção discursiva dos sujeitos às estruturas ideológicas dominantes na sociedade. Da mesma forma que na abordagem anterior, tender-se-ia, nesta perspectiva, a subordinar, de modo, muitas vezes, abusivo, o plano do discurso ao plano social mais amplo.

O sentido pleno dessa série de críticas desenvolvidas por Charaudeau só se revela quando se considera atentamente o compromisso desse autor com a articulação entre os planos lingüístico e situacional. As várias abordagens criticadas por ele podem ter seus méritos específicos, mas não satisfazem à condição proposta por Charaudeau $(1996, \mathrm{p} 9)$ como "princípio do estudo da linguagem": seriam incapazes de pensar "o espaço externo como fundador do espaço interno e, ao mesmo tempo, construído por este" ou, ainda, de "problematizar a linguagem num modelo que constrói o social em sociolinguageiro e o lingüístico em sociodiscursivo" ( $\mathrm{p}$ 21). Dito de outra forma, essas abordagens teriam dificuldade para pensar o situacional como algo que condiciona o plano lingüístico sem chegar a determiná-lo, na medida em que 
esse plano lingüístico, ou propriamente linguageiro, interagiria com o plano situacional, selecionando, atualizando e resignificando seus elementos.

Sinteticamente, essas abordagens não seriam capazes de conceber satisfatoriamente o caminho de mão dupla que vai do situacional ao lingüístico e vice versa. Charaudeau não está falando, simplesmente, da necessidade de se considerar os componentes situacionais e lingüisticos, mas sobretudo de se conceber a relação entre eles. Seu objetivo é, fundamentalmente, a construção de uma abordagem que incorpore, conjuntamente, "uma teoria do situacional em relação com o lingüístico" e "uma teoria do lingüístico em relação com o situacional" (1996, p. 21), ou seja, que esteja voltada, justamente, para os pontos de articulação entre essas duas dimensões da realidade.

\section{A articulação entre os planos situacional e lingüístico}

O primeiro grande compromisso teórico de Charaudeau é, assim, sem dúvida nenhuma, o de conceber os discursos como resultando de uma articulação íntima, bidirecional, não determinista, entre os planos situacional e lingüístico. Esse compromisso é operacionalizado por Charaudeau, em primeiro lugar, através da noção de "contrato de comunicação". Para Charaudeau, todo ato de linguagem realiza-se dentro de um tipo específico de relação contratual, implicitamente reconhecido pelos sujeitos, e que define, por um lado, aspectos ligados ao plano situacional - qual a identidade dos parceiros, seus objetivos, o assunto de que falam, em que circunstâncias materiais - e, por outro, aspectos relativos ao plano comunicacional e discursivo - quais as maneiras de dizer ou quais as estratégias discursivas pertinentes.

Quando se pensa num contrato de comunicação de natureza escolar ou "de sala de aula" (Charaudeau, 1999b), por exemplo, já se espera que um dos participantes (o professor) possua e demonstre um conhecimento e uma identidade profissional específica, que esse participante tenha como objetivo transmitir seus conhecimentos aos sujeitos aos quais ele se dirige, que ele o faça dentro dos limites de tempo e espaço determinados pela dinâmica escolar e, finalmente, que ele utilize maneiras de se expressar apropriadas ao contexto de sala de aula e adequadas aos seus objetivos didáticos. Da mesma forma, espera-se que os sujeitos aos quais o primeiro participante se dirige (os alunos) possuam uma competência específica, tenham o aprendizado como objetivo básico, ajustem-se às circunstâncias materiais de tempo e espaço do contrato e que, também, se sirvam de estratégias discursivas consideradas apropriadas para esse tipo de contrato.

Nos termos de Charaudeau (1999b, p. 6), "o contrato é um quadro de reconhecimento no qual se inscrevem os parceiros para que se estabeleça a troca e a intercompreensão, sendo, portanto, da ordem do imaginário social”. A idéia é que os sujeitos que compartilham um mesmo universo cultural possuiriam um entendimento mais ou menos próximo sobre os vários tipos possíveis de encontro linguageiro (tipos de contrato) e expectativas sobre as identidades típicas dos sujeitos envolvidos, seus prováveis objetivos, os assuntos que eles devem abordar e as maneiras de falar mais prováveis em cada caso. Os sujeitos esperam, em princípio, que todos esses elementos variem conforme o encontro linguageiro em questão possa ser definido como uma entrevista, um discurso político, uma propaganda de algum produto, um debate informal entre amigos e etc. Os contratos de comunicação funcionam, assim, como parâmetros, "códigos implícitos", expectativas compartilhadas e mais ou menos institucionalizadas (compare-se, por exemplo, uma cerimônia de casamento e um debate informal entre amigos) sobre o modo de funcionamento das situações de comunicação e sobre os discursos prováveis em cada tipo de situação. É importante ressaltar que essas expectativas referem-se, simultaneamente, às condições de produção e ao discurso produzido, ou seja, aos componentes situacionais e lingüísticos conjuntamente. Em poucas palavras, um contrato de comunicação é uma definição socialmente estabelecida de quais as condições (identidade dos sujeitos, objetivos legítimos, saberes pertinentes, circunstâncias materiais) apropriadas para se produzir cada tipo de discurso (narrativo, agumentativo, persuasivo, descritivo, com um conjunto ou outro de recursos estilísticos, mais ou menos formal, etc) e, inversamente, que tipo de discurso é adequado para que condições. Trata-se, assim, de uma noção fundamental dentro do objetivo de Charaudeau de articulação entre os componentes lingüístico e situacional.

Os contratos de comunicação não seriam, no entanto, apenas formas gerais e socialmente compartilhadas de se tipificar os vários atos de linguagem. Diferentemente disso, a concepção de Charaudeau é a de que todo intercâmbio linguageiro se organiza concretamente na forma de um contrato de comunicação. Para que esse contrato se estabeleça, é necessário, antes de mais nada, que o sujeito comunicante tenha seu direito de fala reconhecido pelo sujeito interpretante, ou seja, que ele seja considerado um sujeito normal, não alienado, alguém digno de ser escutado. Esse reconhecimento é conquistado pelo sujeito comunicante na medida em que ele consegue apresentar sua identidade, o tema de sua fala e sua motivação para falar de uma forma que possa ser considerada pertinente - no sentido de adequada em relação às representações que o sujeito destinatário faz do mundo - e legítima - no sentido de que o tema e a motivação de sua fala são vistos como adequados em relação a sua identidade individual e coletiva.

Charaudeau (1996, p. 26) define três condições que fundamentam o direito à fala: o reconhecimento do saber, do poder e do saber fazer. Em primeiro lugar, o sujeito comunicante precisa demonstrar que seu discurso refere-se, apropriadamente, a um conjunto de significados ou representações aceitos de uma forma supostamente consensual pelos membros da comunidade da qual faz parte o sujeito destinatário. Em outras palavras, as referências, os saberes utilizados pelo sujeito comunicante precisam ser conhecidos e, então, reconhecidos pelo sujeito interpretante para que o sentido do seu discurso possa ser compreendido e avaliado.

Em segundo lugar, o sujeito comunicante precisa se fazer reconhecer como possuindo determinadas identidades sociais que o legitimam para proferir o discurso em questão. Charaudeau salienta que o grau de legitimidade ou autoridade conferido ao sujeito comunicante depende da maior ou menor adequação que se estabeleça entre sua identidade e status social e o papel linguageiro que ele pretenda desempenhar. A identidade de médico, por exemplo, legitima determinados discursos de um sujeito, mas não lhe confere autoridade para falar, por exemplo, sobre arte ou religião.

Finalmente, em terceiro lugar, Charaudeau observa que o reconhecimento do saber é do poder não bastam em si mesmos. O direito à fala depende ainda do "saber fazer", da capacidade do sujeito comunicante de conquistar a credibilidade dos sujeitos destinatários ao demonstrar que a sua legitimidade, derivada do reconhecimento do saber e do poder, se traduz numa competência específica, ou seja, o sujeito comunicante precisa estar apto para se desempenhar no interior do ato de 
linguagem de uma forma que confirme as expectativas que se fazem sobre ele. A legitimidade de um sujeito decorrente de sua posição profissional, por exemplo, precisaria ser continuamente confirmada pelo modo como ele desempenha seu papel linguageiro.

Fica claro, portanto, que o contrato de comunicação não é algo pronto e definitivo que seja apenas executado pelos sujeitos. Embora seja possível definir as características gerais que diferenciam, por exemplo, os contratos didáticos dos contratos publicitários e se possa, portanto, sustentar uma série de expectativas sobre os componentes situacionais (identidade dos sujeitos, motivação, circunstâncias materiais) e lingüísticos (modos discursivos, formas de tematização, recursos lingüísticos) típicos de cada caso, as características concretas do contrato dependerão sempre das condições específicas de sua realização. Partindo das concepções implicitamente compartilhadas sobre o que caracteriza, em termos situacionais e lingüísticos, cada tipo de ato de linguagem, e portanto, cada tipo de contrato, os sujeitos precisam construir, concretamente, os seus próprios intercâmbios linguageiros. Essa construção, como se viu, depende de um complexo processo de luta pelo reconhecimento do direito à fala, luta essa que inclui a busca do reconhecimento do saber e do poder, e o esforço pela conquista da credibilidade.

\section{A articulação entre os planos macro e microssocial}

É, justamente, ao tratar dessa passagem do abstrato ao concreto, ou seja, ao conceber o processo efetivo de realização de um contrato de comunicação que Charaudeau deixa claro seu segundo grande compromisso teórico, o de evitar uma articulação mecânica ou determinista entre os planos macro e microssocial. As identidades sociais dos parceiros, sua posição nas estruturas macrossociais de poder e prestígio não garantiriam, a priori, o reconhecimento da pertinência e legitimidade de seus discursos.

Em primeiro lugar, a importância (para efeitos discursivos) de cada identidade ou posição social ocupada pelo sujeito comunicante dependeria do tipo de contrato de comunicação que ele pretende estabelecer e do seu projeto de fala no interior desse. A autoridade conferida pela posição do sujeito na estrutura social não seria algo válido, indiscriminadamente, em qualquer situação de comunicação e nem legitimaria qualquer projeto de fala. Oprestígio profissional de um sujeito, por exemplo, pode lhe conferir autoridade para atuar dentro de um contrato de comunicação definido como uma conferência e, no interior desse, lhe autorizar a dar seu parecer sobre os assuntos de sua competência. Esse mesmo prestígio profissional não o legitima, no entanto, para atuar em outros contratos de comunicação e nem o autoriza a realizar outros projetos de fala. Ele não pode, por exemplo, passar (a não ser que sua posição institucional o permita) da simples apresentação do seu parecer profissional à distribuição de ordens ou tarefas aos espectadores. A autoridade decorrente da identidade e das posições ocupadas pelo sujeito comunicante na estrutura social torna-se mais ou menos relevante, portanto, dependendo da situação de comunicação e do projeto específico de fala do sujeito.

Já se vê como Charaudeau faz uma passagem equilibrada entre os planos macro e microssociais. Os atributos decorrentes das posições macroestruturais ocupadas pelos sujeitos só tornam-se relevantes em articulação com as circunstâncias microssociais em que eles atuam. Charaudeau vai, no entanto, ainda mais longe. Não basta a existência de uma adequação entre a localização macroestrutural do sujeito (com os atributos daí decorrentes) e as circunstâncias e objetivos de sua atuação. É necessário que esses atributos sejam reconhecidos pelos sujeitos destinatários para que eles se tornem operantes, e esse reconhecimento ocorre, justamente, dentro do encontro linguageiro, através da interação e avaliação mútua dos interlocutores.

O mérito de Charaudeau aqui é o de acentuar que não se pode passar diretamente, de forma mecânica, das estruturas sociais para as ações dos sujeitos. Apenas uma parte dos determinantes macroestruturais mostra-se relevante em cada situação de comunicação, e mesmo essa parte delimitada só se torna operante a partir de um trabalho, simultaneamente, social e lingüístico de reconhecimento por parte dos interlocutores de sua significação.

\section{A ênfase na interação social}

Já é possível compreender, então, o modo como Charaudeau satisfaz seu terceiro compromisso teórico: o de tratar seriamente a dimensão da interação social. O curso do intercâmbio linguageiro não é visto por ele como predeterminado em relação ao momento da interação entre os participantes. Os sujeitos reagem constantemente às estratégias de fala uns dos outros, avaliam e reavaliam as identidades e as intenções dos interlocutores, definem e redefinem a natureza do contrato no qual estão inseridos, e a partir de tudo isso, constroem conjuntamente o ato de linguagem. Trata-se, portanto, de um modelo dinâmico. É no jogo socialmente condicionado - mas não previamente determinado - da busca do reconhecimento do direito à fala que o discurso se define.

Vale a pena, voltando um pouco ao primeiro compromisso teórico de Charaudeau, observar como esse jogo é simultaneamente lingüístico e situacional. É na interação comunicativa entre os participantes que os componentes situacionais são reconhecidos e se tornam operantes. Ao mesmo tempo, a natureza dessa interação comunicativa só se explica em função da definição social do contrato e das condições efetivas de sua realização, especialmente, a identidade psicossocial dos parceiros, seus projetos de fala, e as circunstâncias materiais do intercâmbio.

É, então, justamente, a ênfase concedida por Charaudeau à interação entre os parceiros que lhe permite operacionalizar seus dois compromissos teóricos anteriores. Seria na interação linguageira que se articulariam os componentes situacionais e lingüísticos e os planos macro e microssocial. Seria por meio da interação, em outras palavras, que o situacional se converteria em linguageiro, ou ainda, que os atributos sociais dos sujeitos seriam reconhecidos ou não como pertinentes à cena discursiva.

Enfatizando o plano da interação social, Charaudeau rompe, na verdade, vale observar, com toda uma tradição de reflexão sobre a linguagem que pensa a construção do sentido como centrada na relação língua/mundo. Alternativamente, Charaudeau propõe-se a pensar o sentido como sendo produzido "numa relação triangular que subordina a referência ao mundo (a proposicional) à intersubjetividade dos interlocutores (a relacional) (1996, p.7). 


\section{Uma intencionalidade socialmente condicionada}

Finalmente, cabe destacar aqui o compromisso de Charaudeau, mencionado no início deste artigo, com uma concepção do sujeito e de sua intencionalidade bastante sofisticada. Ele evita tanto as concepções que enfatizam, unilateralmente, a dimensão da autonomia e liberdade do sujeito quanto as que acentuam a subordinação da consciência individual em relação aos determinantes sociais.

Por um lado, Charaudeau confere aos sujeitos uma dimensão ativa e estratégica. Um ato de linguagem se inicia no momento em que um sujeito motivado por um projeto de fala definido em termo de objetivos comunicacionais (factivo, "fazer fazer"; informativo, "fazer saber"; persuasivo, "fazer crer"; sedutor, "fazer prazer") toma a iniciativa da palavra. O contrato de comunicação reserva a esse sujeito uma margem de manobra dentro da qual ele pode escolher, com uma certa liberdade, as estratégias de fala (as formas de organização do discurso) que ele julgue mais apropriadas para influenciar adequadamente os interlocutores.

Essa dimensão ativa ou estratégica da ação dos sujeitos encontra, por outro lado, na perspectiva de Charaudeau, uma série de limitações. Em primeiro lugar, o sujeito que constrói seu projeto de fala e que seleciona suas estratégias discursivas não é um sujeito qualquer, um ser abstrato, descolado de uma realidade social determinada, mas, ao contrário, é alguém que se orienta em circunstâncias materiais específicas e que se define por uma identidade psicossocial particular. Sua intencionalidade é assim socialmente condicionada.

Em segundo lugar, o projeto e as estratégias de fala do sujeito são constrangidas pelo fato de se dirigirem para um outro sujeito com uma identidade e uma intencionalidade também definidas. Isso exige que, para ser eficiente no seu objetivo de influência, o ser comunicante molde seu projeto e suas estratégias ao conhecimento e às expectativas que ele tem em relação ao comportamento do outro com quem ele pretende interagir.

Por último, vale relembrar que o processo é dinâmico e que, portanto, as reações do interlocutor à fala do sujeito comunicante fazem com que esse último seja obrigado a redefinir constantemente seu projeto e suas estratégias de fala.

Resumidamente, pode-se dizer que o sujeito em Charaudeau encontra-se, por um lado, preso a uma série de constrangimentos relativos às características do contrato e às condições de sua realização. Esses constrangimentos não eliminam, no entanto, uma margem de escolha dentro da qual o sujeito pode agir estrategicamente (1996, p. 100).

\section{O esquema de representação do ato de linguagem: uma síntese da perspectiva de Charaudeau}

Todos os compromissos teóricos discutidos ao longo deste texto revelam-se, de modo sintético, quando tomamos o esquema abaixo (ver fig. 1) de representação do ato de linguagem. Esse esquema, utilizado recorrentemente por Charaudeau (p. ex. 1992, p. 6), propõe, em primeiro lugar, a distinção entre um circuito externo (lugar do fazer) e um circuito interno (lugar do dizer).

No circuito externo, interagem um Eu comunicante (Eu c.), caracterizado por uma identidade psicossocial específica e por um projeto de fala definido (que é necessariamente um projeto de influência sobre o interlocutor), e um Tu interpretante ( $\mathrm{Tu}$ i.) possuidor, igualmente, de uma identidade psicossocial e de uma intencionalidade próprias (presumidas, mas, sempre, parcialmente desconhecidas pelo Eu c.). Esses dois sujeitos empíricos interagem orientados, por um lado, pelo conhecimento que eles já possuem das características típicas do contrato de comunicação que eles estão encenando (expectativas diferenciadas conforme o tipo de contrato) e, por outro, considerando as circunstâncias materiais envolvidas (tempo, espaço, tipo de canal de comunicação, se direto, via escrita, via televisão, etc).

$\mathrm{O}$ ato de linguagem tem início efetivamente no momento em que o Eu c., motivado por seu projeto de fala e servindo-se do seu conhecimento das condições presentes de produção do seu discurso (incluindo aí as expectativas que ele têm sobre a identidade e intencionalidade do Tu i.), seleciona e começa a implementar suas estratégias de fala. O Eu. c., sujeito empírico, converte-se, neste momento, em Eu enunciador (Eu e.), ser da fala, e institui o outro como Tu destinatário (Tu d.), ser existente, apenas, no discurso do Eu e. Passa-se, então, ao circuito interno do ato de linguagem, ao plano propriamente da fala. A interação entre os interlocutores torna-se, aqui, mediada pela palavra. Para que o Tu i. aceite e de continuidade ao contrato de comunicação iniciado pelo Eu c., e mais ainda, para que o Eu c. consiga realizar seu projeto de influência, é necessário que o Eu c. consiga, convertido em Eu e., ser reconhecido no seu saber, no seu poder e no seu saber-fazer.

Esse reconhecimento, como vimos, é algo complexo e sempre instável. O Tu i. pode, a qualquer momento, romper com as expectativas do Eu c. - descolando-se da sua construção discursiva (o Tu d.) - e deslegitimar o projeto de fala do Eu c. Charaudeau (1982, p. 5) oferece um ótimo exemplo disso. Quando uma pessoa ordena a outra que se cale, essa primeira pessoa está se apresentando como alguém que possui autoridade sobre a segunda pessoa. Digamos, para usar os termos de Charaudeau, que o Eu e. está instituindo o Tu d. como ser submisso. O Tu i., no entanto, pode ou não reconhecer a autoridade pretendida pelo Eu c. e enunciada pelo Eu e.. Ele pode tanto se calar, permitindo que o Eu c. seja legitimado e realize seu projeto de influência, como reagir, negando a imagem que o Eu e. fez dele (negando o Tu d.) e rompendo o contrato.

Esse esquema de representação do ato de linguagem proposto por Charaudeau nos permite visualizar como são operacionalizados, em sua obra, os quatro compromissos teóricos e epistemológicos que foram identificados e discutidos neste artigo. Torna-se clara a articulação, operada pelo autor, entre os componentes situacionais e lingüísticos e entre os planos macro e microssociais. Da mesma forma, torna-se patente o papel fundamental, concedido por Charaudeau, a interação entre os parceiros envolvidos. Finalmente, esse esquema nos ajuda a reconhecer a natureza, simultaneamente, estratégica e condicionada da concepção de intencionalidade sustentada pelo autor. 
FIGURA 1: REPRESENTAÇÃO DO ATO DE LINGUAGEM

\section{Circuito externo - Condições de Produção/Interpretação}

Eu C.

$\underline{\text { Identidade psicossocial }}$

$\underline{\text { Projeto de fala }}$
Circuito interno - Discurso

\begin{tabular}{|ll}
$\begin{array}{l}\text { Eu E. } \\
\text { Estratégias de fala }\end{array}$ & Tu D. \\
Perfil pssicossocial (imaginado) \\
$\underline{\text { Modos do discurso }}$ & $\underline{\text { Intencionalidade (imaginada) }}$ \\
$\underline{\text { Tematizacão }}$ &
\end{tabular}

Tema: do que se fala

Dispositivos materiais envolvidos

\section{Referências Bibliograficas}

CHARAUDEAU, Patrick. Eléments de sémiolinquistique d'une théorie du langage à une analyse du discours. connexions, $\mathrm{n}^{\circ} 38,1982$.

. Para uma nova análise do discurso. In: Carneiro, Agostinho Dias (org.). O discurso da mídia. Rio de Janeiro: Oficina do autor, 1996.

. Une analyse sémiolinguistique du discours. Langages, $\mathrm{n}^{\circ} 117,1995$.

.Análise do discurso: controvérsias e perspectivas. IN: MARI, H., PIRES, S., CRUZ, A., \&

MACHADO, I. (orgs.). Fundamentos e dimensões da análise do discurso. Belo Horizonte: Carol Borges, 1999

, O contrato de comunicação em sala de aula. Pratiques, nº especial, 1999b ( tradução e adaptação para fins didáticos Diléa Pires)

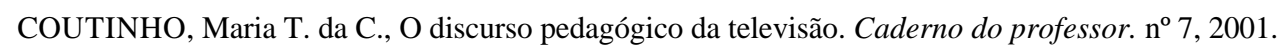

DATA DE RECEBIMENTO: 31/07/04

DATA DE APROVAÇÃO: 15/01/05

\footnotetext{
${ }^{\mathrm{i}}$ Professor de Sociologia da Educação, Fae/UFMG

ii Essas problemáticas, segundo Charaudeau, não correspondem exatamente às correntes teóricas presentes no campo da análise do discurso. Uma mesma corrente poderia, em principio - conforme o autor e a pesquisa específica em questão aproximar-se de mais de uma problemática.

iii Ao criticar a chamada "pragmática lingüística" (1996, p. 11), Charaudeau distingue três perspectivas teóricas diferentes que negligenciam, cada uma a seu modo, a dimensão psicossocial. Duas dessas perspectivas buscariam, em principio, incorporar o plano situacional em suas análises mas o fariam, segundo Charaudeau, de uma forma insatisfatória. A terceira perspectiva, embora reconhecendo a existência desse plano situacional, opta deliberadamente por restringir seu trabalho ao plano propriamente lingüístico.
} 